\title{
A Comparison between Bupivacaine Alone and Bupivacaine with Tramadol in Epidural Block for Postoperative Pain Management
}

\author{
Saadia Khaleeq, ${ }^{1}$ Azib Ali, ${ }^{2}$ Sahir Shafiq, ${ }^{3}$ Muhammad Muazzam Butt, ${ }^{4}$ Mudassar Aslam, \\ Muhammad Usman Jehangir ${ }^{6}$
}

\begin{abstract}
Objective: This study was designed to compare the mean pain score with bupivacaine versus tramadol plus bupivacaine in patients undergoing surgery under general anesthesia. Randomized Controlled Study. Anesthesia department of SIMS medical college/Services Hospital, Lahore. Duration is 13 months from 20th August2017 till 24th September 2018.

Method: 80 patients aged 20-60 years of ASA I \& II status, undergoing elective surgery were selected. Patients were randomly divided into two groups (Group A and B) of 40 each, using random numbers table. An epidural catheter was placed at L3-L4 intervertebral level. Group A was given $30 \mathrm{ml}$ of $0.125 \%$ bupivacaine and Group B was given 25mg Tramadol plus $0.125 \%$ bupivacaine mixture in the same volume. General anesthesia was induced with IV Propofol $2 \mathrm{mg} / \mathrm{kg}$ and atracurium $0.5 \mathrm{mg} / \mathrm{kg}$. After recovery from anesthesia, patients were shifted to HDU. Post-operative pain was assessed using the 10-point VAS score. Injection nalbuphine $0.1 \mathrm{mg} / \mathrm{kg}$ was given as rescue analgesic when VAS score became more than 4 .

Results: The mean age of patient in Group A was 37.5 \pm 9.1 years and 38.6 \pm 7.0 years in Group B. Mean BMI in Group A was 33.2 \pm 4.3 and 32.2 \pm 4.2 in Group B. The mean pain score after 12 hours of surgery was $3.6 \pm$ 0.8 in Group A and $1.5 \pm 0.9$ in Group B, p value was significant.

Conclusion: Thus, the present study concludes that epidural administration of tramadol as adjuvant with bupivacaine is more effective in postoperative pain relief as compared to bupivacaine alone.

Key Words: Bupivacaine, Epidural, Postoperative pain, Tramadol.

How to Cite: Khaleeq S, Ali A, Shafiq S, Butt M M, Aslam M, Jehangir MU. A Comparison between Bupivacaine alone and Bupivacaine with Tramadol in epidural block for postoperative pain management. Esculapio.2021;17(1): page number. Esculapio.2020;16(04):101-104.
\end{abstract}

DOI: https://doi.org/10.51273/esc20.2516422

\section{Introduction}

$\checkmark$ urgical patients require effective intra operative Ns well as post-operative pain control. The aim of postoperative analgesia is to provide patient comfort,

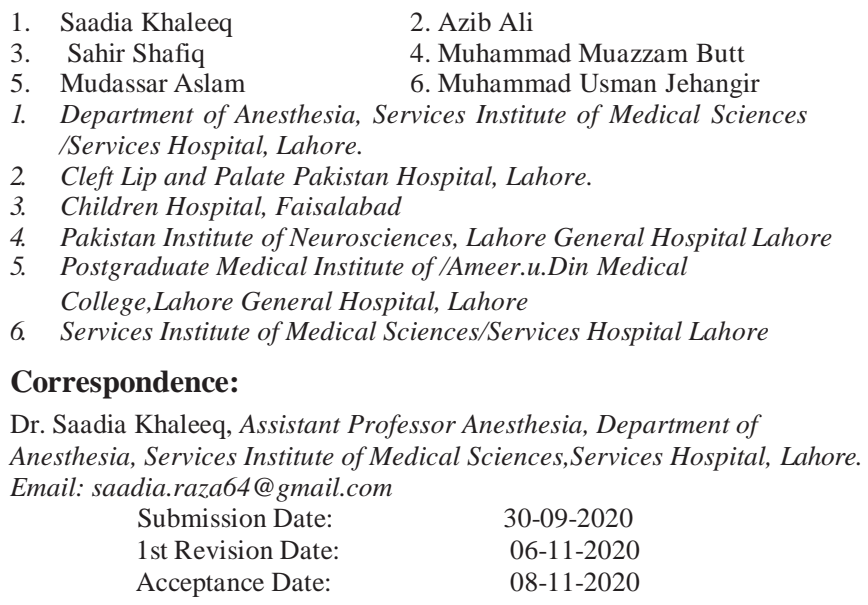

early ambulation and recovery of motor function. ${ }^{1}$ Effective postoperative analgesia decreases the incidence of respiratory and cardiovascular complications, improves patient satisfaction, speeds up recovery and discharge from hospital. ${ }^{2-5}$ High severity of postoperative pain increases the incidence of hospital stay duration, surgical morbidity and mortality. ${ }^{3}$

Regional analgesia with the local anesthetic drug via epidural catheter is established method of satisfactory postoperative pain management. ${ }^{1,6}$ Epidural block gives better control of the level of analgesia, lesser hemodynamic changes and can be used for postoperative pain relief by using different drugs. ${ }^{6,7}$ The choice of individual drug used for epidural analgesia depends upon the factors like severity of pain, presence of co morbid conditions and general condition of the patient. ${ }^{4}$ Bupivacaine is a 
local anesthetic which belongs to the amide group of anesthetic agents that has been widely used for peripheral nerve blocks, spinal and epidural anesthesia. Various adjuvants have been added to the local anesthetic to minimize their side effects and prolong the duration of intraoperative and postoperative analgesia. ${ }^{7}$ Opioids are considered the best option as adjuvants to local anesthetics for postoperative analgesia because of easy availability and convenient use. ${ }^{8}$ Tramadol is a centrally acting opioid analgesic and is similar in structure to morphine and codeine with both active enan-tiomers. It augments the pain transmission inhibition via neurotransmitters modulation: the $(+)$-enantiomer inhibits serotonin reuptake, whereas the (-)enantiomer inhibits norepinephrine reuptake and has no neural toxicity when given intrathecal or in epidural anaesthesia. ${ }^{9,10}$ In addition, the (+)-enantiomer and the primary metabolite of tramadol, (+)-O-desmethyl - tramadol, both act as $\mu$-opioid receptor agonists. ${ }^{11}$ The different properties of the tramadolenantiomers create synergistic analgesic effects, which improves tolerability by decreasing various side effects common to other opioids, such as respiratory depression, constipation, and abuse potential. ${ }^{12}$ The

rationale for managing post-operative pain is to improve the outcome of surgery along with increased patient satisfaction. Earlier studies have revealed the use of systemic and regional analgesics with minimum side effects to be effective in relieving pain. We designed this study to compare the mean pain score with bupivacaine versus tramadol plus bupivacaine in patients undergoing surgery under general anesthesia.

\section{Methods}

Randomized, Controlled Trial. 3 months from 20th August 2017 till 24th September 2018. Anesthesia Department of SIMS Medical College/Services Hospital.

After approval from hospital ethical committee, 80 patients aged 20-60 years of ASA I \& II status, undergoing elective surgery were selected through wards of Department of Surgery, Services hospital, Lahore. Written informed consent was taken. Patients with absolute contra indication for epidural block like bleeding disorder or receiving anticoagulants, allergic to study drugs, infection at the site of injection and neurological deficit were excluded from study.
Patients were randomly divided into two groups (Group A and B) of 40 each using random numbers table. A $20 \mathrm{G}$ cannula was passed and standard monitors were applied after receiving the patient in operation theatre. Before administering general anesthesia, an epidural catheter was placed with Tuohy needle after loss of resistance technique at L3-L4 intervertebral space level. After a test dose of $3 \mathrm{ml}$ xylocaine containing epinephrine (1:200,000), Group A was given $30 \mathrm{ml}$ of $0.125 \%$ bupivacaine and Group B was given $25 \mathrm{mg}$ Tramadol plus $0.125 \%$ bupivacaine in the same volume of $30 \mathrm{ml}$. Anaesthesia was then induced with IV Propofol $2 \mathrm{mg} / \mathrm{kg}$ and tracheal intubation was done with atracurium $0.5 \mathrm{mg} / \mathrm{kg}$. General anaesthesia was maintained with $50 \% \mathrm{O}_{2}+50 \% \mathrm{~N}_{2} \mathrm{O}$ and $1.2 \%$ isoflurane with IPPV. At completion of surgery, patients were recovered from anesthesia and shifted to high dependency unit, where they were followed-up for 12 hours. After 12 hours, post-operative pain was assessed using the 10-point VAS score. No pain-0, 1-3-mild pain, 4-7-moderate pain, and $8-10$-severe pain. Injection nalbuphine $0.1 \mathrm{mg} / \mathrm{kg}$ was given as rescue analgesic in patients with VAS score of more than 4.

\section{Data Analysis}

SPSS version 21 was used to enter and analyze the data. Quantitative variable like age, BMI and postoperative pain were represented by mean \pm SD. Qualitative variable like gender were presented by calculating frequency and percentage. Both groups were compared for postoperative pain by using independent sample t-test. P-value $\leq 0.05$ was considered as significant.

\section{Results}

The mean age of patient in Group A was 37.5 \pm 9.1 years. In group B mean age was 38.6 \pm 7.0 years. Age was comparable for both groups. Mean BMI in Group A was $33.2 \pm 4.3$ and $32.2 \pm 4.2$ in Group B. BMI distribution was equal in both groups. Table 1.

There were 38 males and 42 females making $47.5 \%$ and $52.5 \%$ of sampled population. Male female distribution was almost equal. (Figure:1) The mean pain score after twelve hour of surgery was $3.6 \pm 0.8$ in Group A and 1.5 \pm 0.9 in Group B, p value was significant. Table 2. Data stratification for age group and mean pain score was not significant. Table 3 


\section{Discussion}

More than $80 \%$ of patients suffer from acute postoperative pain after surgical procedure. The severity of pain is categorized as moderate, severe or extreme by $75 \%$ of patients. Adequate pain relief has been reported in literature by less than half number of patients. Persistent postsurgical pain leads to increased risk of post-surgical complications, delay in recovery and thus quality of life will be affected with inadequate control of pain. ${ }^{13,14}$ The goal of modern

Table 1: Demographic Data

\begin{tabular}{lcc}
\hline & $\begin{array}{c}\text { Group A } \\
\text { (Bupivacaine) }\end{array}$ & $\begin{array}{c}\text { Group B } \\
\text { (Bupivacaine \& } \text { Tramadol) }\end{array}$ \\
\hline Age & $37.15 \pm 9.11$ & $38.65 \pm 7.04$ \\
BMI $\left(\mathrm{kg} / \mathrm{m}^{2}\right)$ & $33.26 \pm 4.36$ & $32.29 \pm 3.31$ \\
\hline
\end{tabular}

Table 2: Comparison of pain scroing in Group A, Gourp B

\begin{tabular}{|c|c|c|c|}
\hline & \multicolumn{3}{|c|}{ (Bupivacaine) (Bupivacaine\&Tramadol) value } \\
\hline $\begin{array}{l}\text { Pain Score } \\
\text { Mean } \pm \text { SD }\end{array}$ & $3.650 \pm 0.833$ & $1.525 \pm 0.960$ & 0.000 \\
\hline \multicolumn{4}{|c|}{$\begin{array}{l}\text { Table 3: Comparison of Pain Scoring in different age } \\
\text { Group }\end{array}$} \\
\hline $\begin{array}{l}\text { Age } \\
(\text { years })(B\end{array}$ & $\begin{array}{l}\text { Group A } \\
\text { upivacaine) (B }\end{array}$ & $\begin{array}{l}\text { Group B } \\
\text { aine\&Trama }\end{array}$ & $\begin{array}{l}\text { p- } \\
\text { alue }\end{array}$ \\
\hline $20-35$ & $3.94 \pm 0.63$ & $1.50 \pm 0.61$ & 0.438 \\
\hline $35-60$ & $3.40 \pm 0.90$ & $1.54 \pm 1.18$ & 0.609 \\
\hline
\end{tabular}

postoperative pain management is to minimize suffering and enhance recovery and rehabilitation through blunting maladaptive reflexes. ${ }^{15}$ Many preoperative, intraoperative, and postoperative strategies are being used to control postoperative pain. ${ }^{13,14}$ Most commonly used is epidural analgesia because of its various advantages. The major advantage is the use of lower doses of analgesic drugs with prolonged duration of action and minimal side effects. ${ }^{15}$ In our study lower VAS scores were found with combination of bupivacaine plus tramadol administered epidurally $(p<0.05)$. Similar results were seen by Saxena D et al who also noticed lower pain scores with epidural tramadol+bupivacaine and concluded that it provided better analgesia than bupivacaine alone in patients undergoing lower limb surgeries. ${ }^{6}$

Comparable observations were seen by Pavithra who conducted study on pediatric population and compared bupivacaine alone versus tramadol plus bupivacaine. Duration of analgesia was maximum in combination therapy and there was less need for rescue analgesia in combination therapy group. ${ }^{16}$ Likewise, Akhtar $\mathrm{N}$ et al supported the tramadol-ropi-vacaine combination to be effective than ropivacaine alone in lowering the pain scores when used in supraclavicular block for upper limb surgeries. ${ }^{11}$ Singh et al. also revealed significant lower VAS scores with epidural tramadol as adjuvant to $0.2 \%$ ropivacaine in upper abdominal surgeries. ${ }^{1}$ Consistent with our results, Imam A et al observed lower VAS pain scores in their study with tramadol via epidural route when compared to bupivacaine for postoperative analgesic effect in gyneacological surgeries. ${ }^{17}$ In agreement to our study results, Yadhuraj MK et al found lower pain scores after 12 hours. He compared tramadol with pentazocine when given epidurally for postoperative analgesia in lower abdominal surgeries. ${ }^{18}$ Conflicting results have been seen in few studies which could be attributed to choice of local anes-thetics, choice of adjuvants used and methodology. Higher VAS scores were seen by Agarwal et al with Tramadolbupivacaine (4.4) after 4.5 hours under-going TKR and THR surgeries under combined spinal epidural anesthesia. ${ }^{2}$ Patil et al did not find mean VAS score to be lower in tramadol-bupivacaine when compared to fentanyl-bupivacaine group. This was contradictory to our study results which could be due to variation in methodology. ${ }^{4}$ Contrary to our study results, Deo et al also found VAS scores to be significantly higher in Tramadol group. The reason for this variation could be that comparison was done with Butorphanolbupivacaine combination and not with bupivacaine alone. ${ }^{15}$ There were few limitations in our study like sedation score and adverse effects of Tramadal were not measured in our study. Moreover, we could not compare its analgesic effects with other opioid and nonopioid adjuvants. Future studies can be done with other newer drugs to assess their efficacy for epidural analgesia.

\section{Conclusion}

Thus, the present study concludes that epidural administration of tramadol as adjuvant with bupivacaine is more effective in postoperative pain relief as compared to bupivacaine alone.

\section{Conflict Of Interest; None.}

\section{References}

1. Singh AP, Singh D, Singh Y, Jain G. Postoperative analgesic efficacy of epidural tramadol as adjutant to 
ropivacaine in adult upper abdominal surgeries. Anesth Essay Res 2015;9(3):369.

2. Agrawal V, Gore R, Kawade DB, Shelke P. Comparative Study of Tramadol Vs Nalbuphine as an Additive With $0.125 \%$ Bupivacaine Plain for PostOperative Epidural Analgesia in Total Knee Replacement and Total Hip Replacement Surgeries. (IOSRJDMS 2019;18(9):54-58.

3. Shilpashri AM, et al. Postoperative Epidural Analgesia between $0.25 \%$ Ropivacaine Plus Tramadol and $0.25 \%$ Bupivacaine Plus Tramadol in Abdominal and Lower Limb Surgeries - A Comparative Study. Anaesth Critic Care Med J 2019;4(2): 000152.

4. Patil S, Birnale A, Patil S, Patil P. A Comparative study of epidural Fentanyl with Bupivacaine \& epidural Tramadol with Bupivacaine for post operative pain relief after lower abdominal Surgery. JMSCR 2018;6(4): 1268-1275.

5. Adem AO, Obsa MS, Worji TA. Assessments of health professionals knowledge towards post-operative pain management in Asella Teaching and Referral Hospital, South East Ethiopia. IJMMS 2017; 9(11): 137-41.

6. Saxena D, Sanwatsarkar S, Dixit A, Arya B. Comparative study of duration of analgesia with epidural bupivacaine and bupivacaine with tramadol in lower limb surgeries. Int J Res Med Sci. 2017;5(5):20032010

7. Chatrath V, Attri JP, Bala A, et al. Epidural nalbuphine for postoperative analgesia in orthopedic surgery. Anesthesia, Essays and Researches. 2015 SepDec; 9(3):326-330.

8. Kim SY, Kim NK, Baik SH, Min BS, Hur H, Lee J, et al. Effects of postoperative pain management on immune function after laparoscopic resection of colorectal cancer: A randomized study. Medicine 2016;95(19).

9. Sekandarzad MW, van Zundert AA, Doornebal CW, Hollmann MW. Regional anesthesia and analgesia in cancer care: is it time to break the bad news? Curr Opin Anesthesiol 2017;30(5):606-12.

10. Siddiq S, Asad N, Rehman A, Ali M, Khalid U, Butt Z. A comparative study of the effect of intrathecal tramadol and buprenorphine used as adjuvants to hyperbaric bupivacaine for postoperative analgesia in infraumbilical surgeries. APICARE 2019; 23(3): 263-67.

11. Akhtar N, Butt A, Nazeer T, Shah A, Zarqa. Comparison of efficacy of ropivacaine alone with tramadol ropivacaine combination in supraclavicular brachial plexus bock for upper limb surgery. Biomedica 2015; 31(4):281-85.

12 Wolfe AM, Kennedy LH, Na JJ, Nemzek-Hamlin JA. Efficacy of tramadol as a sole analgesic for postoperative pain in male and female mice. J Am Assoc Lab Animal Sci 2015;54(4):411-9.

13. Sharrock NE, Cazan MG, Hargett MJ, WilliamsRusso P, Wilson PD., Jr Changes in mortality after total hip and knee arthroplasty over a ten-year period. Anesth Analg. 1995;80:242-248.

14. Katz J, Jackson M, Kavanagh BP, Sandler AN. Acute pain after thoracic surgery predicts long-term postthoracotomy pain. Clin J Pain. 1996;12:50-55.

15. Deo GP, Shrestha SK, Shrestha IN. Epidural butorphanol for post operative analgesia in lower limb surgeries: a comparative study with epidural tramadol. JCMC 2016; 6(17): 26-32.

16. Pavithra V. Comparison of Caudal Bupivacaine, Bupivacaine with Fentanyl and Bupivacaine with Tramadol Administration for Post Operative Analgesia in Children. Journal of Anesthesia \& Intensive Care Medicine. 2018;6(2).

17. Imam MA, Hasnat S. Bupivacaine versus tramadol: a clinical comparison of two anaesthetics administered via epidural route for postoperative analgesic effect in gynaecological surgeries. Int J Adv Med 2016; 3: 602-6.

18. Yadhuraj MK, Somasekharam P, Vinay DM, RaoAUK. A comparative study of epidural tramadol with epidural pentazocine for postoperativeanalgesia in patients undergoing lower abdominal surgeries. Int J Basic Clin Pharmacol 2017;6:2441-5

\section{Author's Contribution}

KS: Basic design

AA: Data analysis

SS: Discussion writing

BMM: Interpretation \& data analysis

MA: Final drafting of manuscript

JUM: Final approval of revision 
